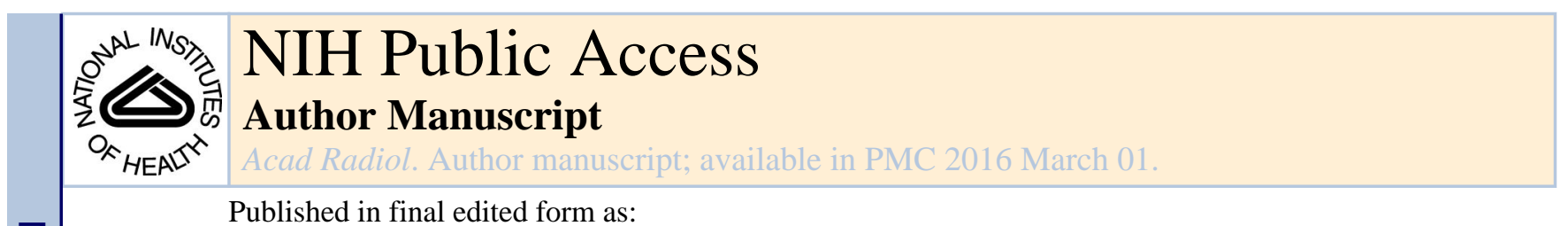

Published in final edited form as:

Acad Radiol. 2015 March ; 22(3): 278-289. doi:10.1016/j.acra.2014.09.013.

\title{
The influence of mammographic technologists on radiologists' ability to interpret screening mammograms in community practice
}

\author{
Louise M. Henderson, MSPH PhD ${ }^{1,2}$, Thad Benefield, MS ${ }^{1}$, Mary W. Marsh, MPH ${ }^{1}$, Bruce F. \\ Schroeder, MD ${ }^{1,3,4}$, Danielle Durham, MPH${ }^{2}$, Bonnie C. Yankaskas, PhD ${ }^{1}$, and J. Michael \\ Bowling, PhD 5 \\ ${ }^{1}$ Department of Radiology, The University of North Carolina, Chapel Hill, NC 27599 \\ ${ }^{2}$ Department of Epidemiology, The University of North Carolina, Chapel Hill, NC 27599 \\ ${ }^{3}$ Carolina Breast Imaging Specialists, Greenville NC 27599 \\ ${ }^{4}$ Departments of Radiology and Oncology, The Brody School of Medicine at East Carolina \\ University, Greenville NC 27834 \\ ${ }^{5}$ Department of Health Behavior, The University of North Carolina, Chapel Hill, NC 27599
}

\section{Abstract}

Purpose-To determine whether the mammographic technologist has an effect on the radiologists' interpretative performance of screening mammography in community practice.

Materials and Methods-In this institutional review board approved retrospective cohort study, we included Carolina Mammography Registry (CMR) data from 372 radiologists and 356 mammographic technologists from 1994 to 2009 who performed 1,003,276 screening mammograms. Measures of interpretative performance (recall rate, sensitivity, specificity, positive predictive value $\left(\mathrm{PPV}_{1}\right)$, and cancer detection rate $\left.(\mathrm{CDR})\right)$ were ascertained prospectively with cancer outcomes collected from the state cancer registry and pathology reports. To determine if the mammographic technologist influenced the radiologists' performance, we employed mixed effects logistic regression models, including a radiologist-specific random effect and taking into account the clustering of examinations across women, separately for screen-film mammography (SFM) and full field digital mammography (FFDM).

Results-Of the 356 mammographic technologists included, 343 performed 889,347 SFM examinations and 51 performed 113,929 FFDM examinations, and 38 performed both SFM and FFDM. A total of 4,328 cancers were reported for SFM and 564 cancers for FFDM. The technologists had a statistically significant effect on the radiologists' recall rate, sensitivity,

\section{(C) 2014 AUR. All rights reserved.}

Address for correspondence, Louise M. Henderson, MSPH PhD, Department of Radiology, CB 7515, The University of North Carolina, Chapel Hill, NC 27599-7515, Tel 919.843.7799, Fax 919.966.0525, Louise_Henderson@med.unc.edu.

Publisher's Disclaimer: This is a PDF file of an unedited manuscript that has been accepted for publication. As a service to our customers we are providing this early version of the manuscript. The manuscript will undergo copyediting, typesetting, and review of the resulting proof before it is published in its final citable form. Please note that during the production process errors may be discovered which could affect the content, and all legal disclaimers that apply to the journal pertain. 
specificity and CDR for both SFM and FFDM (p-values $<0.01$ ). For $\mathrm{PPV}_{1}$, variability by technologist was observed for SFM ( $\mathrm{p}$-value $<0.0001$ ) but not for FFDM ( $\mathrm{p}$-value=0.088).

Conclusion-The interpretative performance of radiologists in screening mammography varies substantially by the technologist performing the examination. Additional studies should aim to identify technologist characteristics that may explain this variation.

\section{Introduction}

Breast cancer is the most common cancer in women, excluding cancers of the skin, and is expected to account for an estimated 232,670 cases and 40,000 deaths in the US in 2014.(1) Routine screening mammography is the primary means of early breast cancer detection with radiologic technologists fulfilling an essential role in the mammography process. While routine screening mammography has proven effective in reducing breast cancer mortality(2), many factors lead to variability in interpretative performance by radiologists.(3-6)

Several studies have found radiologists' gender, work patterns, post residency training, years of experience, specialization, and screening versus diagnostic mix influence mammography performance measures.(3, 7-12) It is also likely that the radiologists' ability to interpret mammograms is affected by technologists who work with the radiologists. Possible sources of variation in radiologists' interpretative ability may include the interface between the radiologist and technologist and the ability of the radiologic technologist to obtain a high quality image in terms of positioning, compression, and sharpness.

Prior studies have examined the performance of technologists as pre-readers or double readers of screening mammography in conjunction with radiologists. In general, the use of technologists as pre or double readers for screening mammograms led to increased cancer detection rates (CDR) without significantly increased recall or false positive rates.(13-17) To our knowledge, no studies have examined the extent of variability among radiologists' screening mammography performance by the technologist performing the exam. Hence, we used 15 years of community based mammography data to determine whether the performance characteristics of screening mammography differ by technologist for screenfilm mammography (SFM) and full field digital mammography (FFDM) separately.

\section{Material and Methods}

The Carolina Mammography Registry (CMR) has collected prospective data from mammography facilities in North Carolina since 1994. Information includes characteristics of women, reason for the breast-imaging visit, breast cancer risk factors, imaging procedures performed, radiologist's findings, assessments and management recommendations. These data are linked with the state cancer registry and pathology data to allow for calculation of standard performance measures including recall rate, sensitivity, specificity, positive predictive value of recall $\left(\mathrm{PPV}_{1}\right)$, and cancer detection rate (CDR). For each mammogram performed at CMR participating facilities, a unique technologist code was collected. These technologist codes allow for the identification of technologists over time and across CMR participating facilities. 


\section{Study Population}

The study included 1,012,491 bilateral screening mammograms among women ages 18 and older, with no personal history of breast cancer and no breast implants, from CMR participating facilities, between January 1, 1994 and December 31, 2009. We excluded 9,215 screening mammograms in which the technologist performed fewer than 50 exams per year or were active for less than 6 months. This gave a total of 1,003,276 screening mammograms that were performed by 356 technologists, interpreted by 372 radiologists, and performed at 59 facilities.

\section{Definitions}

Using standard definitions, we defined a screening mammogram as a bilateral, two view mammogram indicated as screening by the radiologist.(18) Each mammogram interpretation was classified as positive or negative based on the radiologists' Breast Imaging Reporting and Data System (BI-RADS) screening assessment result. We defined an exam positive for recall if the initial BI-RADS assessment was 0 (additional imaging required), 4 (needs evaluation), 5 (highly suggestive of malignancy), or 3 (probably benign) with a recommendation for immediate evaluation. We defined a negative interpretation as BIRADS of 1 (negative), 2 (benign finding), or 3 (probably benign) with no recommendation for immediate evaluation. $(19,20)$ We used data from the North Carolina Central Cancer Registry (NCCCR) as well as pathology data from CMR participating mammography facilities and the University of North Carolina at Chapel Hill's Lineberger Comprehensive Cancer Center's Rapid Case Ascertainment program to identify breast cancer cases. Women were considered to have breast cancer if a diagnosis of invasive carcinoma or ductal carcinoma in situ occurred within one year of the screening mammogram.(21) From the radiologists' BI-RADS interpretation and the cancer diagnosis, each mammogram was classified as true positive (positive mammogram with cancer diagnosed in the follow-up period), false positive (positive mammogram with no cancer diagnosed in the follow-up period), true negative (negative mammogram with no cancer diagnosed in the follow-up period), or false negative (negative mammogram with cancer diagnosed in the follow-up period).

Information on the patient and image characteristics collected at the time of mammography included patient age, patient race, mammographic breast density, family history of breast cancer (defined as at least one first degree relative with breast cancer), history of breast procedure, time since last mammographic exam, and year of exam. Breast density was categorized by the interpreting radiologist according to the BI-RADS assessments of almost entirely fat, scattered fibroglandular densities, heterogeneously dense, or extremely dense.

Performance measures included recall rate, sensitivity, specificity, $\mathrm{PPV}_{1}$, and CDR of the screening mammogram. Recall rate was defined as the percentage of screening mammograms with findings interpreted as positive. Sensitivity was defined as the proportion of those with a positive screening mammogram interpretation among all those with a breast cancer diagnosis within the one-year follow-up period. Specificity was defined as the percentage of screening mammograms with findings interpreted as negative among all 
patients who did not receive a breast cancer diagnosis in the follow-up period. $\mathrm{PPV}_{1}$ was defined as the percentage of positive mammograms that resulted in a breast cancer diagnosis. CDR was defined as the number of true-positive mammograms for every 1,000 screening mammograms.

\section{Statistical Analysis}

We describe the characteristics of the mammograms included in the study, separately for FFDM and SFM examinations. We also provide the average number of screening mammograms performed per technologist by modality. In addition, we computed the mean performance measure and $95 \%$ confidence intervals $(95 \% \mathrm{CI})$ for recall rate, sensitivity, specificity, $\mathrm{PPV}_{1}$, and CDR.

For each performance measure, we fit a mixed effects logistic regression model to evaluate variability across technologists. The models included both technologist-specific and radiologist-specific random effects. By including both the technologist-specific and radiologist-specific random effects, we were able to partition the variance arising from differences in technologists and radiologists, quantifying the variance in performance measures by technologist after controlling for variance arising at the radiologist level. Since some women had multiple examinations, we also modeled a compound symmetric residual variance structure to account for the fact that examinations within a woman were likely correlated. We assessed variation of the performance measures across technologists by conducting likelihood ratio tests, using the residual pseudolikelihood.(22)

This retrospective cohort study is compliant with the Health Insurance Portability and Accountability Act as well as approved by the Institutional Review Board with a waiver of consent.

\section{Results}

From 1994 to 2009 a total of 1,003,276 screening mammograms, $88.6 \%(\mathrm{n}=889,347)$ SFM and $11.4 \%(n=113,929)$ FFDM, were performed (Table 1$)$. The majority of examinations were performed among women ages 40-59 years. Approximately 16-18\% of screening mammograms were performed among African-American women and $8-11 \%$ reported a family history of breast cancer. Breast density was similar among those with SFM and FFDM examinations. Of the SFM, 21\% reported having a prior breast biopsy or breast surgery, compared with $24 \%$ in the FFDM group. The majority of women had a prior mammogram within 1-2 years. As expected, the number of SFM increased until the introduction of FFDM in CMR practices in 2003.

Overall, 372 radiologists interpreted 1,003,276 screening mammograms performed by 356 technologists, with 343 technologists performing SFM, 51 technologists performing FFDM, and 38 technologists performing both. The mean number of screening mammograms per year was 650.5 (range from 53.4 to 3,095.7) for technologists performing SFM exams, 872.4 (range 52.4 to 3,433.4) for technologists performing FFDM exams, and 657.6 (range 52.4 to 3,433.4) for technologists performing both SFM and FFDM examinations. 
The recall rate per 100 examinations was higher for FFDM compared to SFM (10.5 versus 8.1 , respectively) (Table 2). There were no significant differences in the mean sensitivity or mean $\mathrm{PPV}_{1}$ for SFM and FFDM. However, the specificity was lower among FFDM examinations compared to SFM examinations (89.8\% versus 92.2\%). The mean CDR per 1000 examinations was 4.1 for FFDM and 3.8 for SFM.

Smoothed plots of model based performance measures of the studies done by technologist and imaging modality, adjusted for the radiologist interpreting the examination are shown in Figures 1-5. Each set of plots shows the range of performance measures among the studies done by technologists, adjusted for radiologists, for SFM (Figures 1A-5A) and FFDM (Figures 1B-5B). For example, in Figure 1A, sensitivity ranges from 0.66 to 0.92 among the studies done by technologists, with a median of 0.82 , even after adjusting for the radiologist effect. From the figures, the variability in each performance measure is shown and suggests heterogeneity in the results of screening mammograms by technologist. There appears to be more variability in the performance measures of SFM compared with FFDM. The results of the likelihood ratio tests indicate that the technologists had a statistically significant effect on the radiologists' recall rate, sensitivity, specificity and CDR for both SFM and FFDM (pvalues $<0.01$ ) (Table 3 ). For $\mathrm{PPV}_{1}$, variability by technologist was observed for SFM (pvalue $<0.0001$ ) but not FFDM (p-value=0.088).

\section{Discussion}

Interpretive performance of screening mammography is known to vary by patient $(4,23-$ $25)$, radiologist $(4-7,9,11,24-30)$, and facility level characteristics. $(30,31)$ However, the extent to which screening mammography performance varies by the radiologic technologist has yet to be investigated. In this cohort study, we found significant variability in recall rates, sensitivity, specificity, and CDR of screening mammography by the radiologic technologist who did the imaging, while controlling for the radiologist interpreting the examination. This observed variability did not differ by imaging modality (SFM/FFDM). Interestingly, for $\mathrm{PPV}_{1}$ variability by technologist was observed for SFM but not FFDM.

Patient level factors that have been shown to be associated with screening mammography performance include age, breast density, screening history, previous biopsy, menopausal status, current hormone replacement therapy use, and family history of breast cancer. $(4,23$, 24) Radiologist level factors found to affect performance include time since graduation from residency, breast-imaging fellowship/training, annual interpretative volume, years of mammographic imaging and interpretation, and primary affiliation with an academic medical center.(4-7, 9, 24-26, 28-30) Facility level characteristics that may affect performance include volume, screening versus diagnostic mammography mix, having breast imaging specialists interpreting the examinations, and having audits two or more times per year. $(30,31)$ Despite numerous studies examining the patient, radiologist, and facility characteristics, variation in performance measures still exist and perhaps it is due to the radiologic technologist obtaining the image.

Although our study did not examine specific technologist characteristics, as it was beyond the scope of this paper, we suspect that technologists' work experiences, various levels of 
training and education, and interactions with radiologists may affect the performance of screening mammography in community practice. One way in which this may occur is by radiologic technologists assisting radiologists in the interpretation of screening mammograms, which has been explored in multiple studies.(13-16, 32-41) A 2006 U.S. study by Leader et al. examined the use of mammography technologists in providing limited, nonclinical interpretation of screening mammograms as part of a telemammography program.(32) The technologists served as pre-readers for locations with no radiologist on site, thus attempting to reduce the number of women recommended for additional screening through increased technologist and radiologist communication. The study found that technologists were sensitive, but not specific, to mammography features and breast changes that may result in recalling women for additional imaging procedures. In another U.S. study, 33 technologists were evaluated for their ability to accurately classify screening mammograms as negative or requiring additional follow-up.(33) The overall agreement between technologists and radiologists was $82 \%$. Although some studies have shown that having radiologic technologists review screening mammograms prior to the radiologist may increase the number of breast cancers detected, there is no consensus regarding this practice.

Radiologic technologists may also play a role in community level mammography screening adherence. Several focus group studies have examined this and found significant roles of the mammographic technologist. Patient satisfaction with the mammography experience was associated with treatment by the technologist in a study of 103 women in rural and urban communities.(42) A 2013 focus group study of 53 American Indian/Alaska native women in Kansas reported that having a technologist who was friendly, knowledgeable, respectful, competent and willing to explain the screening examination was a determining factor in satisfaction with mammography.(43) In another study aimed at identifying ways to increase patient adherence of screening mammography, survey responses suggested an expansion of the technologist role to that of a breast health educator, with a focus on decreasing patient anxiety, increasing the patient's understanding of the procedure, and discussing the importance of regular screening.(44)

There is likely a learning curve for technologists as they transition from SFM to FFDM, similar to that observed for radiologists. To assess the impact of a 6-month learning curve on our results we conducted a sensitivity analysis in which we excluded FFDM examinations conducted in the first 6 months after a facility converted from SFM to FFDM. Variability in the performance measures by technologist persisted for all performance measures except sensitivity, which declined to non-significance (p-value from 0.027 to 0.128 ). This indicates that the technologist variability observed for sensitivity is likely attributable to the fact that technologists had different learning curves after the transition from SFM to FFDM.

Clearly the technologist plays a critical role in mammography screening, with the potential to affect the performance of radiologists' interpretation, increase patient experience and thus screening adherence. Radiology technologists are required to maintain qualifications for performing mammographic screening. The Mammography Quality Standard Act (MQSA) requires that all mammographic examinations be performed by radiologic technologists who (1) before April 28, 1999 qualified as a radiologic technologist or (2) completed at least 40 contact hours of documented training specific to mammography under the supervision of a 
qualified instructor.(45) The MQSA continuing education requirements for radiologic technologist mammography specific training include teaching or completing at least 15 continuing education units in mammography during the 3 years immediately preceding the facility's annual MQSA inspection date.(46) Furthermore, as part of MQSA continuing experience requirements, radiologic technologists are required to perform a minimum of 200 mammography examinations in the 24 months immediately preceding the date of the facility's annual MQSA inspection. In contrast, MQSA requires radiologists to interpret 960 mammograms every 2 years. Technologists who exceed the requirements may have a positive effect on the performance measures of the radiologists. How the technologist communicates and works with the radiologists is an important area for further research.

\title{
Study Limitations
}

Although our study includes over 350 technologists from community practice, these technologists are from North Carolina and thus our study results may not be generalizable to other geographic areas. Another limitation is that we did not take reading strategy into account. We do not expect this to alter our findings since only $5.9 \%$ of SFM and $0.7 \%$ of FFDM examinations were double read. We did not evaluate the specific technologist characteristics that may influence the observed variability since this information is not currently available. We are currently conducting a survey of mammography technologists to obtain data on technologist training/education, work experiences, interactions with radiologists, and job satisfaction for future analyses.

\section{Conclusion}

Our study findings indicate that the technologist carrying out the examination influenced radiologists' recall rate, sensitivity, specificity, and CDR of screening mammography. Given that the technologist is an integral part of the screening mammography process, being responsible for positioning the patient for the examination and generating the image for the radiologist to interpret, our findings seem reasonable. Additional studies should aim to identify technologist characteristics that may explain this observed variation.

\section{Acknowledgment}

\author{
Funding \\ This work was supported by funding from the National Institute of Health, National Cancer Institute under grant \\ R01CA155342 and U01CA70040. \\ We thank all the participating facilities in the registry and the women who underwent mammography at these \\ facilities. Without these women, this work would not have been possible.
}

\section{References}

1. Society AC. , editor. American Cancer Society. What are the key statistics about breast cancer?. 2013.

2. National Cancer Institute. Breast Cancer Screening (PDQ). Bethesda, MD: National Cancer Institute; 2010.

3. Miglioretti DL, Smith-Bindman R, Abraham L, et al. Radiologist characteristics associated with interpretive performance of diagnostic mammography. J Natl Cancer Inst. 2007; 99:1854-1863. [PubMed: 18073379] 
4. Elmore JG, Miglioretti DL, Reisch LM, et al. Screening mammograms by community radiologists: variability in false-positive rates. J Natl Cancer Inst. 2002; 94:1373-1380. [PubMed: 12237283]

5. Barlow WE, Chi C, Carney PA, et al. Accuracy of screening mammography interpretation by characteristics of radiologists. J Natl Cancer Inst. 2004; 96:1840-1850. [PubMed: 15601640]

6. Carney PA, Elmore JG, Abraham LA, et al. Radiologist uncertainty and the interpretation of screening. Med Decis Making. 2004; 24:255-264. [PubMed: 15155014]

7. Elmore JG, Jackson SL, Abraham L, et al. Variability in interpretive performance at screening mammography and radiologists' characteristics associated with accuracy. Radiology. 2009; 253:641-651. [PubMed: 19864507]

8. Elmore JG, Wells CK, Howard DH. Does diagnostic accuracy in mammography depend on radiologists' experience? J Womens Health. 1998; 7:443-449. [PubMed: 9611702]

9. Molins E, Macia F, Ferrer F, Maristany MT, Castells X. Association between radiologists' experience and accuracy in interpreting screening mammograms. BMC Health Serv Res. 2008; 8:91. [PubMed: 18439248]

10. Esserman L, Cowley H, Eberle C, et al. Improving the accuracy of mammography: volume and outcome relationships. J Natl Cancer Inst. 2002; 94:369-375. [PubMed: 11880475]

11. Beam CA, Layde PM, Sullivan DC. Variability in the interpretation of screening mammograms by US radiologists. Findings from a national sample. Arch Intern Med. 1996; 156:209-213. [PubMed: 8546556]

12. Elmore JG, Wells CK, Lee CH, Howard DH, Feinstein AR. Variability in radiologists' interpretations of mammograms. N Engl J Med. 1994; 331:1493-1499. [PubMed: 7969300]

13. van den Biggelaar FJ, Flobbe K, van Engelshoven JM, de Bijl NP. Pre-reading mammograms by specialised breast technologists: legal implications for technologist and radiologist in The Netherlands. Eur J Health Law. 2009; 16:271-279. [PubMed: 19788004]

14. Wivell G, Denton ER, Eve CB, Inglis JC, Harvey I. Can radiographers read screening mammograms? Clin Radiol. 2003; 58:63-67. [PubMed: 12565207]

15. Pauli R, Hammond S, Cooke J, Ansell J. Radiographers as film readers in screening mammography: an assessment of competence under test and screening conditions. Br J Radiol. 1996; 69:10-14. [PubMed: 8785616]

16. Bassett LW, Hollatz-Brown AJ, Bastani R, Pearce JG, Hirji K, Chen L. Effects of a program to train radiologic technologists to identify abnormalities on mammograms. Radiology. 1995; 194:189-192. [PubMed: 7997550]

17. Haiart DC, Henderson J. A comparison of interpretation of screening mammograms by a radiographer, a doctor and a radiologist: results and implications. Br J Clin Pract. 1991; 45:43-45. [PubMed: 1931542]

18. Breast Cancer SurveillanceConsortium Glossary of Terms. Data Dictionary Version 5.0. Seattle, WA: Breast Cancer Surveillance Consortium; 2009.

19. Taplin SH, Ichikawa LE, Kerlikowske K, et al. Concordance of breast imaging reporting and data system assessments and management recommendations in screening mammography. Radiology. 2002; 222:529-535. [PubMed: 11818624]

20. American College of Radiology. Illustrated Breast Imaging Reporting and Data System (BIRADS). Reston, VA: American College of Radiology; 1998.

21. Rosenberg RD, Yankaskas BC, Abraham LA, et al. Performance benchmarks for screening mammography. Radiology. 2006; 241:55-66. [PubMed: 16990671]

22. Wolfinger R, O'Connell M. Generalized linear mixed models a pseudo-likelihood approach. Journal of Statistical Computation and Simulation. 1993; 48:233-243.

23. Carney PA, Cook AJ, Miglioretti DL, et al. Use of clinical history affects accuracy of interpretive performance of screening mammography. J Clin Epidemiol. 2012; 65:219-230. [PubMed: 22000816]

24. Cook AJ, Elmore JG, Miglioretti DL, et al. Decreased accuracy in interpretation of communitybased screening mammography for women with multiple clinical risk factors. J Clin Epidemiol. 2010; 63:441-451. [PubMed: 19744825]

25. Miglioretti DL, Gard CC, Carney PA, et al. When radiologists perform best: the learning curve in screening mammogram interpretation. Radiology. 2009; 253:632-640. [PubMed: 19789234] 
26. Buist DS, Anderson ML, Haneuse SJ, et al. Influence of annual interpretive volume on screening mammography performance in the United States. Radiology. 2011; 259:72-84. [PubMed: 21343539]

27. Geller BM, Bowles EJ, Sohng HY, et al. Radiologists' performance and their enjoyment of interpreting screening mammograms. AJR Am J Roentgenol. 2009; 192:361-369. [PubMed: 19155395]

28. Smith-Bindman R, Chu P, Miglioretti DL, et al. Physician predictors of mammographic accuracy. J Natl Cancer Inst. 2005; 97:358-367. [PubMed: 15741572]

29. Tan A, Freeman DH Jr, Goodwin JS, Freeman JL. Variation in false-positive rates of mammography reading among 1067 radiologists: a population-based assessment. Breast Cancer Res Treat. 2006; 100:309-318. [PubMed: 16819566]

30. Theberge I, Hebert-Croteau N, Langlois A, Major D, Brisson J. Volume of screening mammography and performance in the Quebec population-based Breast Cancer Screening Program. CMAJ. 2005; 172:195-199. [PubMed: 15655240]

31. Taplin S, Abraham L, Barlow WE, et al. Mammography facility characteristics associated with interpretive accuracy of screening mammography. J Natl Cancer Inst. 2008; 100:876-887. [PubMed: 18544742]

32. Leader JK, Hakim CM, Ganott MA, et al. A multisite telemammography system for remote management of screening mammography: an assessment of technical, operational, and clinical issues. J Digit Imaging. 2006; 19:216-225. [PubMed: 16710798]

33. Sumkin JH, Klaman HM, Graham M, et al. Prescreening Mammography by Technologists: A Preliminary Assessment. American Journal of Roentgenology. 2003; 180:253-256. [PubMed: 12490515]

34. Tonita JM, Hillis JP, Lim CH. Medical radiologic technologist review: effects on a populationbased breast cancer screening program. Radiology. 1999; 211:529-533. [PubMed: 10228538]

35. Apffelstaedt J, Steenkamp V, Baatjes K. Surgeon-Read Screening Mammography: An Analysis of 11,948 Examinations. Annals of Surgical Oncology. 2010; 17:249-254. [PubMed: 20853042]

36. Duijm LEM, Groenewoud JH, Fracheboud J, de Koning HJ. Additional Double Reading of Screening Mammograms by Radiologic Technologists: Impact on Screening Performance Parameters. J Natl Cancer Inst. 2007; 99:1162-1170. [PubMed: 17652282]

37. Duijm LEM, Groenewoud JH, Fracheboud J, van Ineveld BM, Roumen RMH, de Koning HJ. Introduction of additional double reading of mammograms by radiographers: Effects on a biennial screening programme outcome. European Journal of Cancer. 2008; 44:1223-1228. [PubMed: 18400488]

38. Duijm LEM, Louwman MWJ, Groenewoud JH, van de Poll-Franse LV, Fracheboud J, Coebergh JW. Inter-observer variability in mammography screening and effect of type and number of readers on screening outcome. Br J Cancer. 2009; 100:901-907. [PubMed: 19259088]

39. Moran S, Warren-Forward H. A retrospective study of the performance of radiographers in interpreting screening mammograms. Radiography. 2011; 17:126-131.

40. Mucci B, Lawson S, Athey G, Scarisbrick G. Radiographers as readers in breast screening: experience with a 'red dot' method. The Breast. 1997; 6:183-185.

41. Alcorn FS, O'Donnell E, Ackerman LV. The Protocol and Results of Training Nonradiologists to Scan Mammograms. Radiology. 1971; 99:523-529. [PubMed: 4397087]

42. Engelman KK, Cizik AM, Ellerbeck EF. Women's satisfaction with their mammography experience: results of a qualitative study. Women Health. 2005; 42:17-35. [PubMed: 16782674]

43. Ndikum-Moffor FM, Braiuca S, Daley CM, Gajewski BJ, Engelman KK. Assessment of mammography experiences and satisfaction among american indian/alaska native women. Womens Health Issues. 2013; 23:e395-e402. [PubMed: 24183414]

44. Fox SA, Klos DS, Worthen NJ, Pennington E, Bassett LW, Gold RH. Improving the adherence of urban women to mammography guidelines: strategies for radiologists. Radiology. 1990; 174:203206. [PubMed: 2294548]

45. US Food and Drug Administration. Mammography Quality Standards Act and Program Policy Guidance Help System: U.S. Food and Drug Administration. 2013. Radiologic Technologist Mammography Specific Training. 
46. [Accessed April 15, 2014] FDA - MQSA Rules and Regulations. Available at https:// www.radcomm.net/regulations/. 


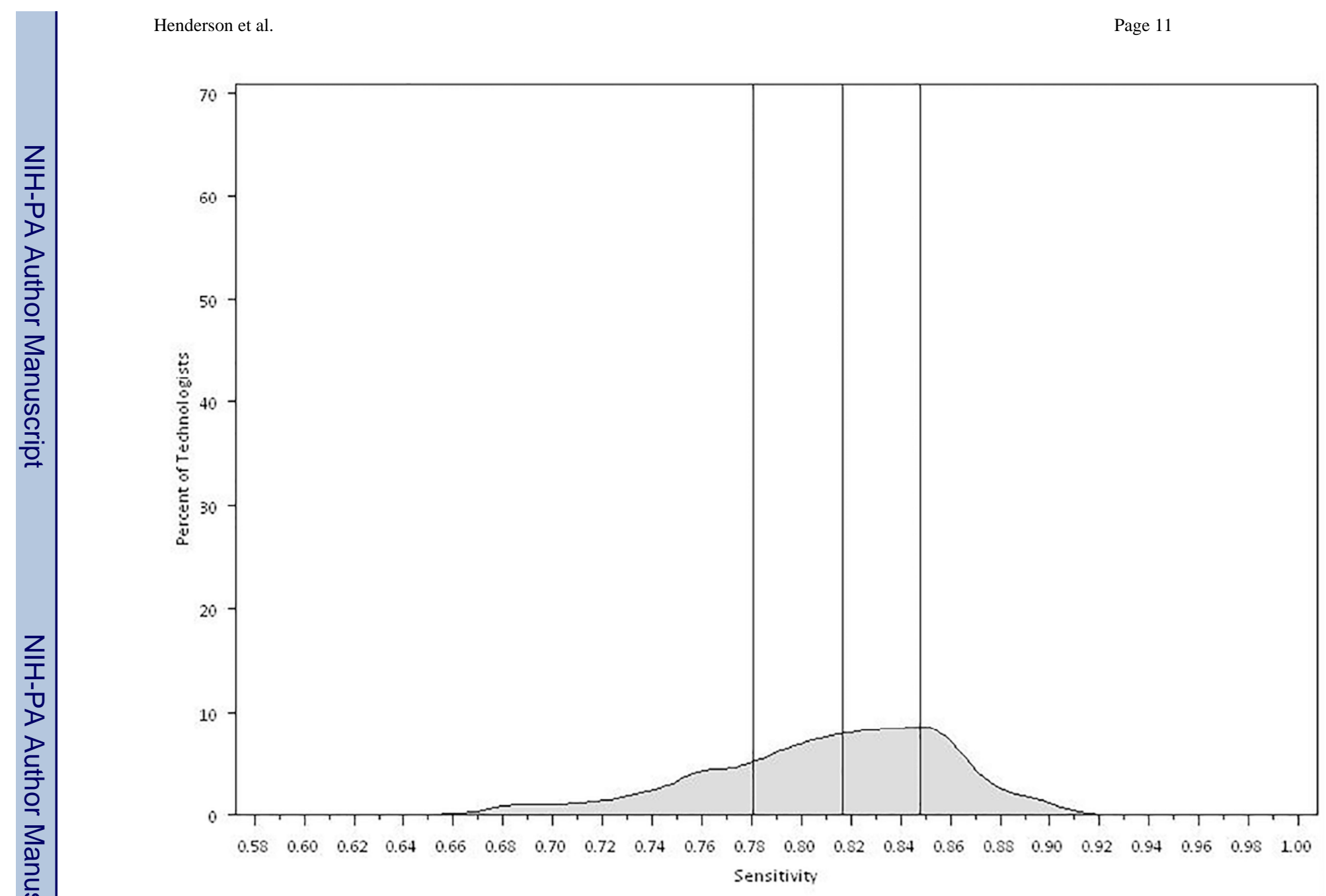

Acad Radiol. Author manuscript; available in PMC 2016 March 01. 


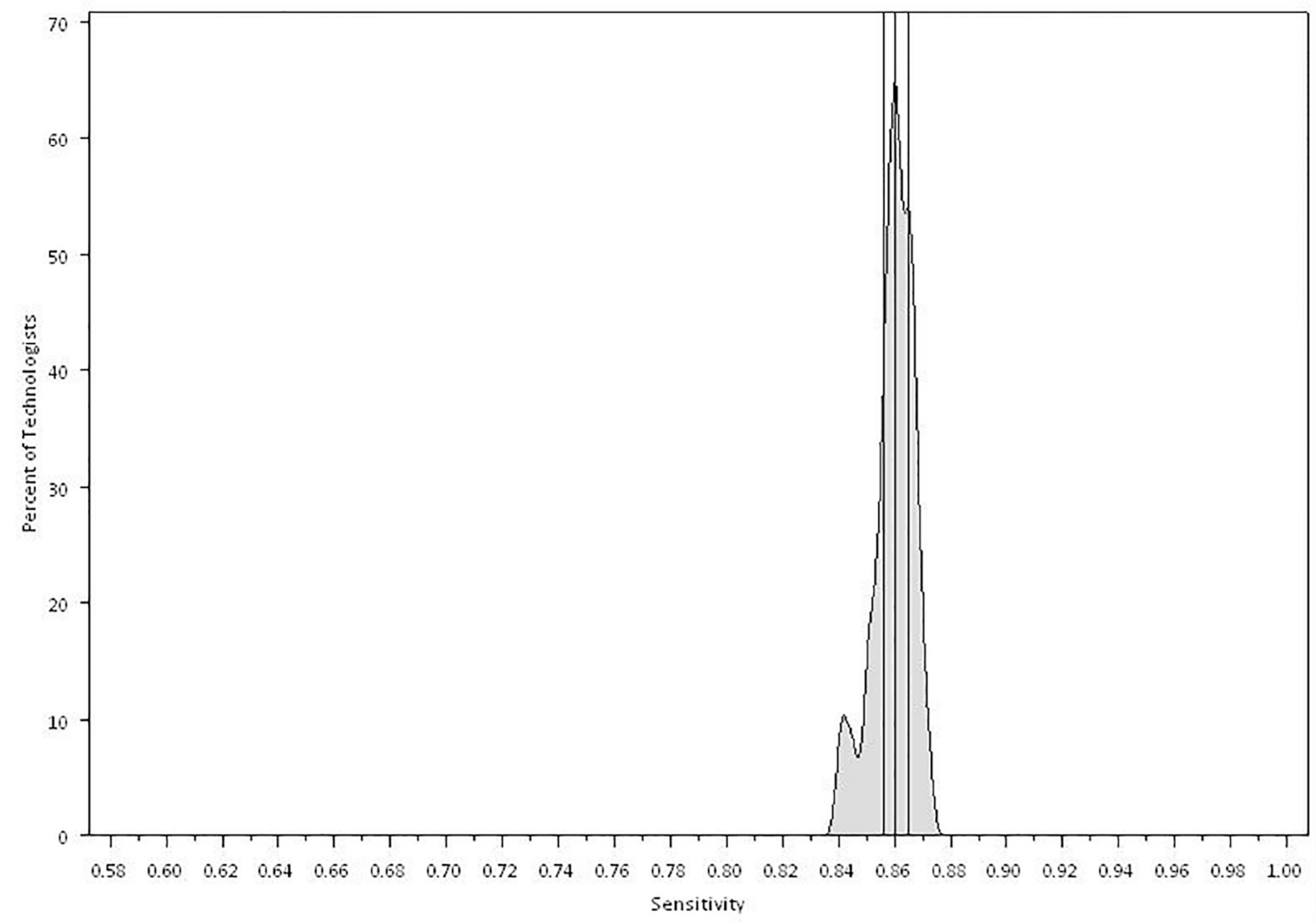

Figure 1.

Model-based smoothed histograms of screening mammography sensitivity for the 356 technologists by modality (SFM and FFDM) with solid vertical lines at $25^{\text {th }}, 50^{\text {th }}$, and $75^{\text {th }}$ quartiles; A. SFM, B. FFDM. 


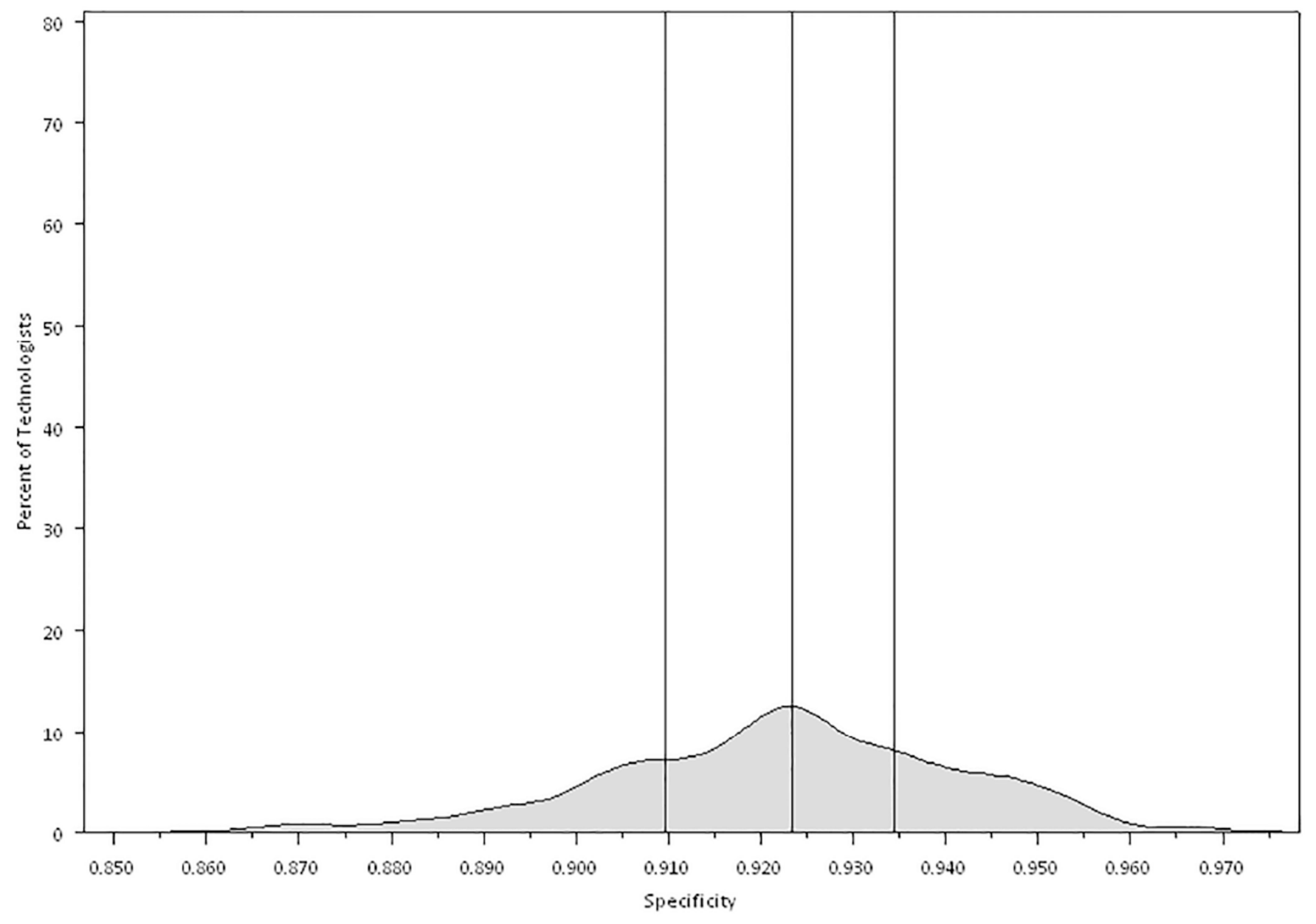

Acad Radiol. Author manuscript; available in PMC 2016 March 01. 


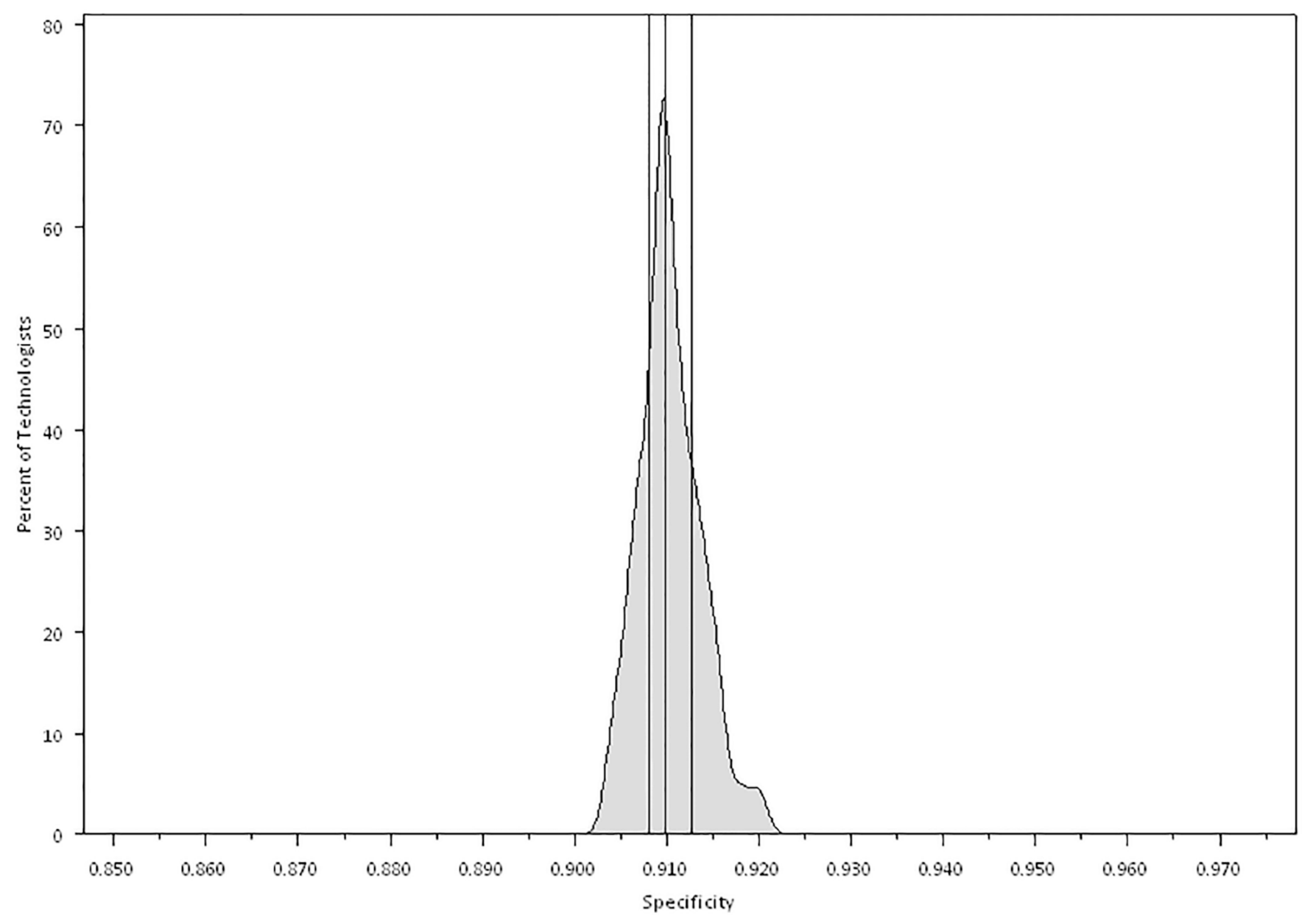

Figure 2.

Model-based smoothed histograms of screening mammography specificity for the 356 technologists by modality (SFM and FFDM) with solid vertical lines at $25^{\text {th }}, 50^{\text {th }}$, and $75^{\text {th }}$ quartiles; A. SFM, B. FFDM. 


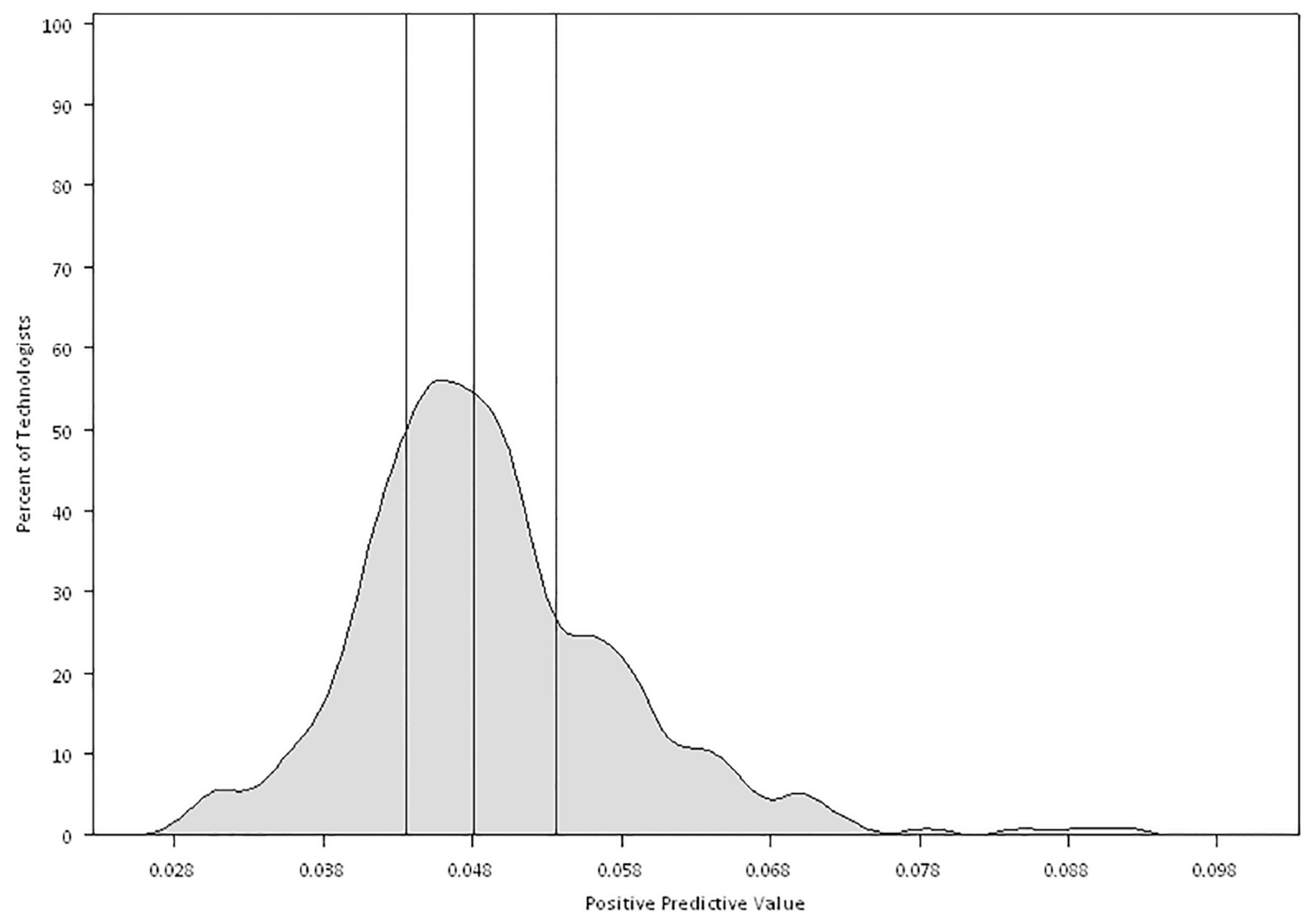

Acad Radiol. Author manuscript; available in PMC 2016 March 01. 


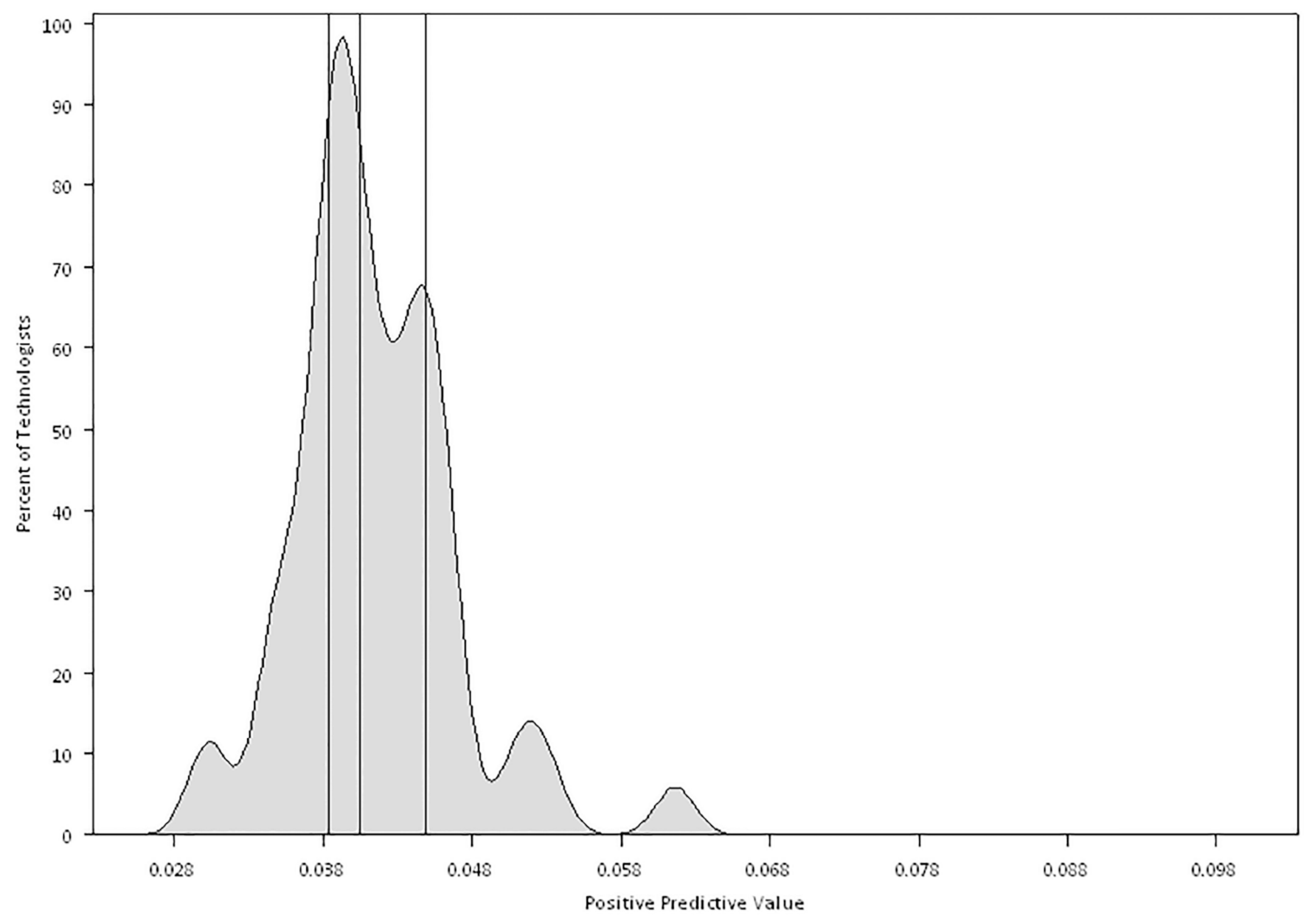

Figure 3.

Model-based smoothed histograms of screening mammography positive predictive value for the 356 technologists by modality (SFM and FFDM) with solid vertical lines at $25^{\text {th }}, 50^{\text {th }}$, and $75^{\text {th }}$ quartiles; A. SFM, B. FFDM. 


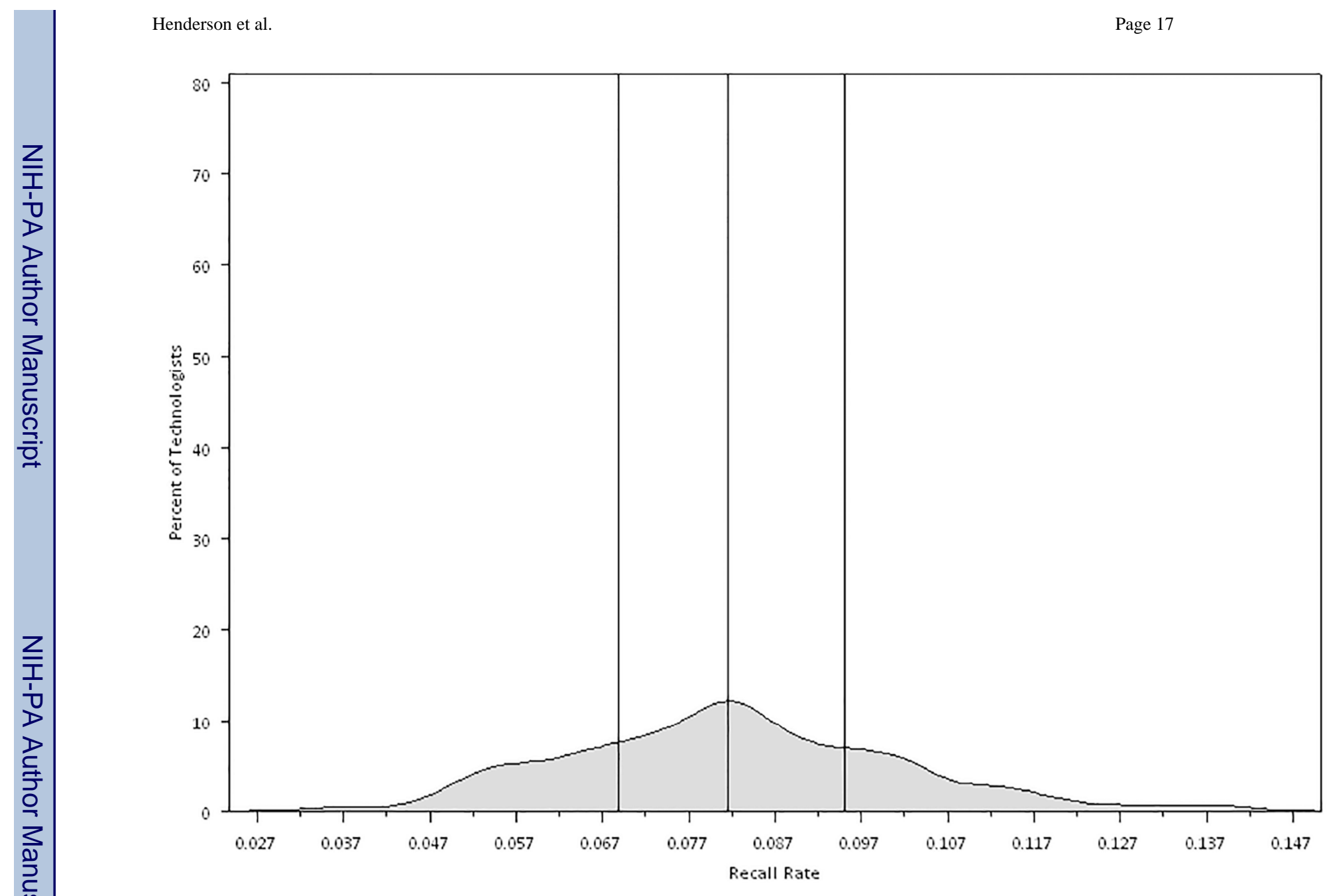

Acad Radiol. Author manuscript; available in PMC 2016 March 01. 


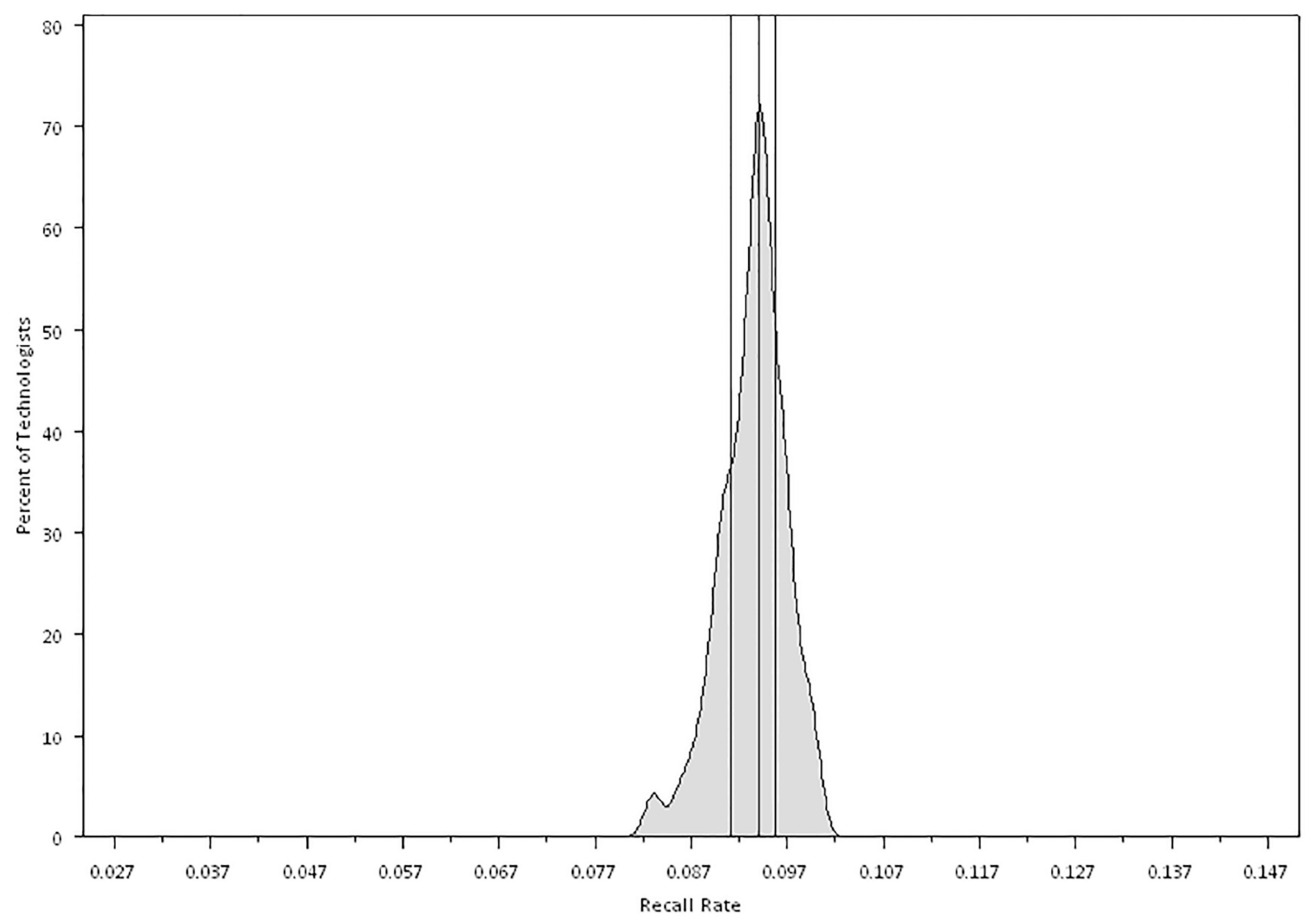

Figure 4.

Model-based smoothed histograms of screening mammography recall rate for the 356 technologists by modality (SFM and FFDM) with solid vertical lines at $25^{\text {th }}, 50^{\text {th }}$, and $75^{\text {th }}$ quartiles; A. SFM, B. FFDM. 


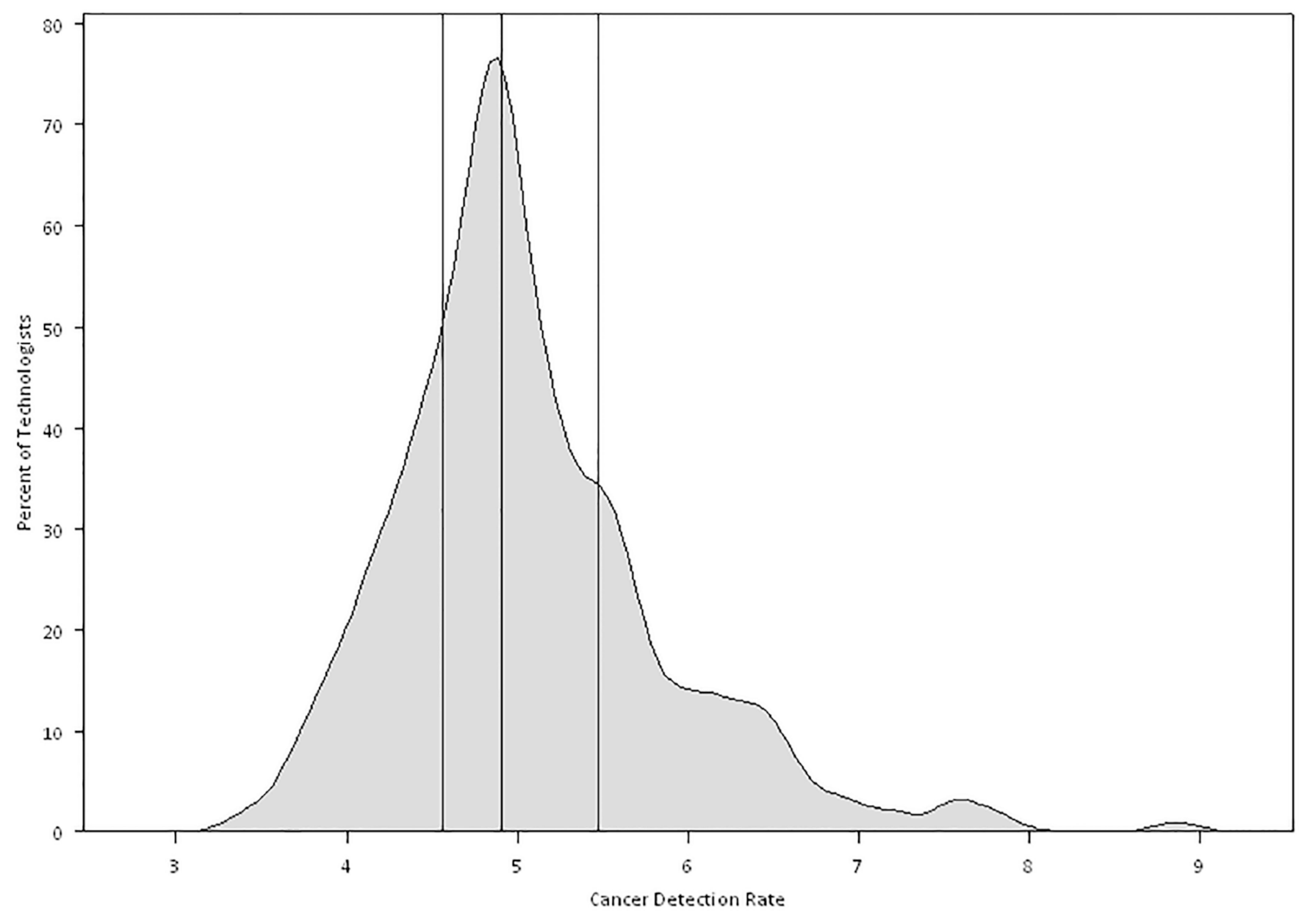

Acad Radiol. Author manuscript; available in PMC 2016 March 01. 


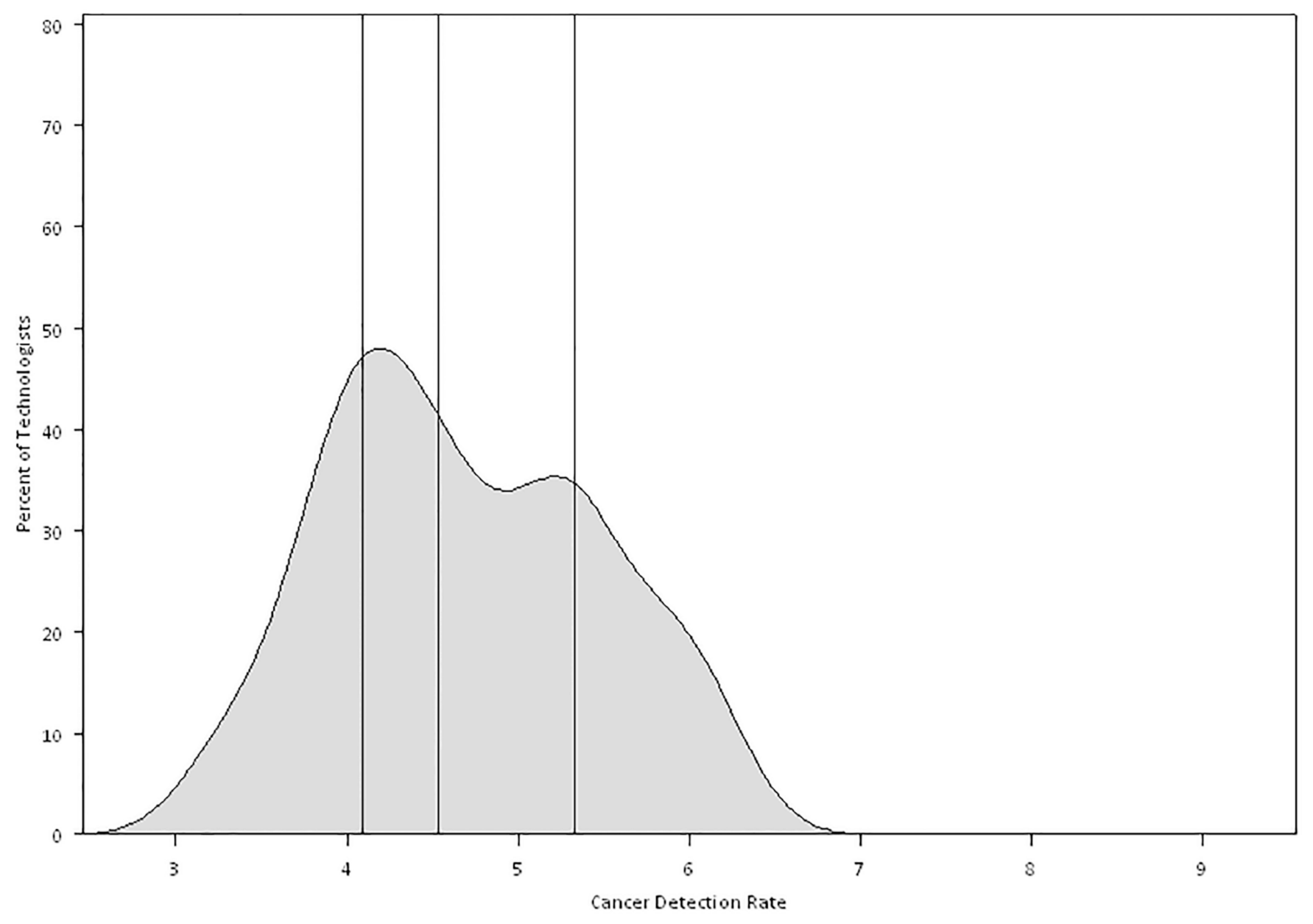

Figure 5.

Model-based smoothed histograms of screening mammography cancer detection rate for the 356 technologists by modality (SFM and FFDM) with solid vertical lines at $25^{\text {th }}, 50^{\text {th }}$, and $75^{\text {th }}$ quartiles; A. SFM, B. FFDM. 

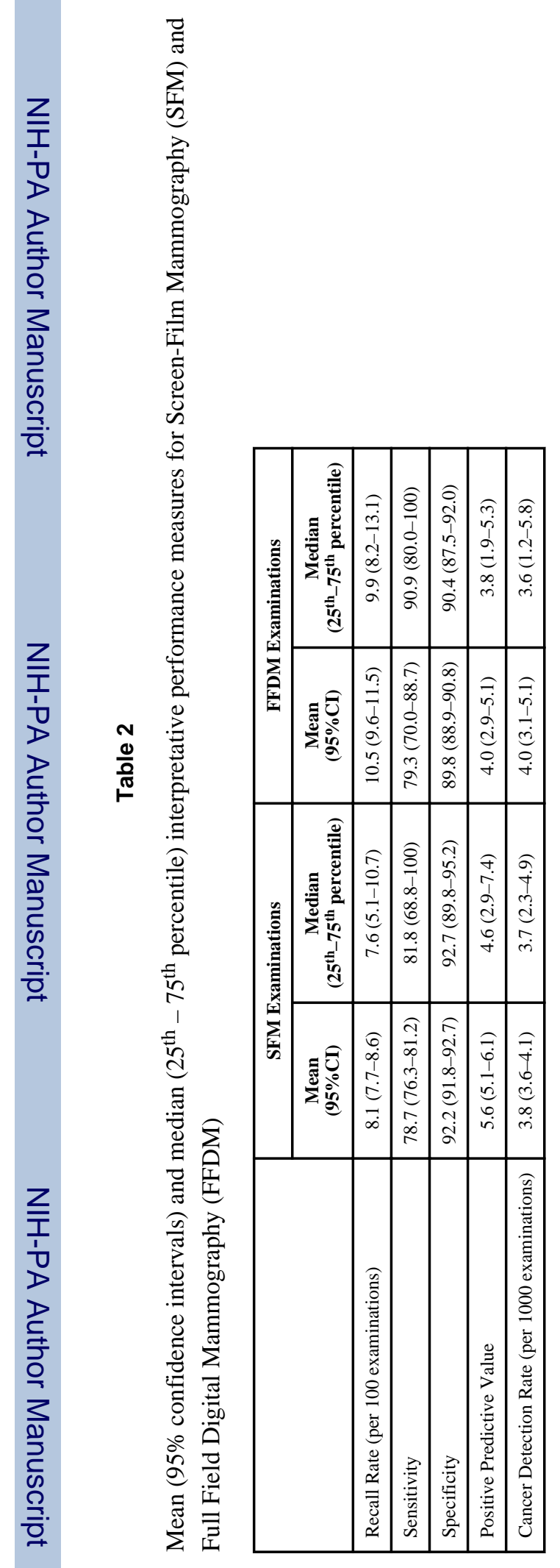

Acad Radiol. Author manuscript; available in PMC 2016 March 01. 


\section{Table 3}

Resulting p-values from mixed effects logistic regression models assessing variability of performance measures by technologist

\begin{tabular}{|l|c|c|}
\hline Performance Measure & $\begin{array}{c}\text { SFM Examinations } \\
\mathbf{N}=\mathbf{8 8 9 , 3 4 7}\end{array}$ & $\begin{array}{c}\text { FFDM Examinations } \\
\mathbf{N = 1 1 3 , 9 2 9}\end{array}$ \\
\hline Recall Rate & $<0.0001$ & 0.001 \\
\hline Sensitivity & $<0.0001$ & 0.019 \\
\hline Specificity & $<0.0001$ & 0.003 \\
\hline Positive Predictive Value & $<0.0001$ & 0.088 \\
\hline Cancer Detection Rate & $<0.0001$ & 0.0001 \\
\hline
\end{tabular}

SFM = screen-film mammography; FFDM = full field digital mammography 